Article

\title{
Evaluation and Origin Discrimination of Two Monocultivar Extra Virgin Olive Oils, Cultivated in the Coastline Part of North-Western Greece
}

\author{
Vasiliki Skiada ${ }^{1,2, *}$, Sofia Agriopoulou ${ }^{1}$, Panagiotis Tsarouhas ${ }^{3}$, Panagiotis Katsaris ${ }^{2}$, \\ Eygenia Stamatelopoulou ${ }^{1}$ and Theodoros Varzakas ${ }^{1, *}$ \\ 1 Department of Food Science and Technology, University of the Peloponnese, 24100 Kalamata, Greece; \\ sagriopoulou@gmail.com (S.A.); estamatel@gmail.com (E.S.) \\ 2 Department of Olive and Horticultural Plants, Hellenic Agricultural Organization-DEMETER, \\ 24100 Kalamata, Greece; pankatsaris@yahoo.gr \\ 3 Department of Supply Chain Management (Logistics), International Hellenic University, \\ 60100 Katerini, Greece; ptsarouhas@ihu.gr \\ * Correspondence: vpskiada@yahoo.gr (V.S.); tvarzakas@us.uop.gr (T.V.)
}

Received: 7 September 2020; Accepted: 24 September 2020; Published: 25 September 2020

\begin{abstract}
Extra virgin olive oil (EVOO) quality and authenticity are important and challenging factors nowadays for the assurance of consumers' protection, prevention of unfair competition, and disruption of the national economy by a false declaration of origin. Hence, the recognition of EVOO authenticity is of great interest in terms of commercial and quality aspects. The objective of this study was to evaluate and discriminate monovarietal extra virgin olive oils of the two dominant olive cultivars, Lianolia Kerkyras and Koroneiki, produced in the coastline part of Western Greece, based on their chemical characteristics, followed by statistical and chemometric analysis in order to profile for the first time the typical characteristics of Lianolia Kerkyras as well as to identify possible markers for authenticity purpose. A total of 104 olive oil samples were collected. Both cultivars had an overall high quality profile as far as their basic qualitative parameters (free fatty acid, peroxide value, and UV spectrometric indices) are concerned. A higher concentration in the mono-unsaturated oleic acid characterize olive oils of cv. Koroneiki compared to cv. Lianolia Kerkyras, while a clearly higher concentration in the poly-unsaturated linoleic acid was observed in olive oils of cv. Lianolia Kerkyras. In addition, olive oil samples of cv. Koroneiki showed a clear lower total sterols concentration with a percentage of $40.9 \%$ not surpassing the required EU Regulatory limit of $1000 \mathrm{mg} / \mathrm{kg}$, an observation which strengthens previous published results of our research group and depicts an overall "intrinsic characteristic" of cv. Koroneiki. As far as the profile of the individual sterols is concerned, Lianolia Kerkyras samples exhibited higher mean value for the total sterol content as well as for $\beta$-sitosterol, the major phytosterol in olive oils, compared to the relative values of Koroneiki. Significant differences in the sterolic and fatty acid composition of the examined olive oil samples were shown by means of statistical analysis demonstrating a strong botanical effect and depicting that those compositional markers can be suggested as possible authenticity tools.
\end{abstract}

Keywords: olive oil; cv. Lianolia Kerkyras; cv. Koroneiki; fatty acid methyl esters; sterols; authenticity; quality

\section{Introduction}

Extra virgin olive oil (EVOO) is cherished as a fundamental ingredient not only in the Mediterranean diet but also internationally due to its proven health-promoting effects and nutritional 
properties [1-3]. This worldwide olive oil reputation is the major driving force for a continuously higher demand on the international olive oil consumption [4,5]. As a matter of fact, the exported olive oil quantities are continuously increasing not only from the main olive-oil producing counties (Spain, Italy and Greece) but also from non-traditional producing countries around the world such as Argentina, Australia, and China [6].

In this context, the demand of higher quality olive oils has led to the continuous appearance in the market of olive oils elaborated with specific and unique characteristics. Hence, the European Union (EU) has established a series of regulations for the certification, protection, and guarantee of the quality and authenticity of olive oils arising from unapproved and fraudulent activities [7-11]. Protected Designation of Origin (PDO) and Protected Geographical Indication (PGI) are two of the main systems created by EU in order to promote and protect food product's authenticity [12]. These denominations require precise definition of several parameters such as cultivar, geographical origin, agronomic practice, and production technology. From the above-mentioned parameters, the cultivar is of utmost importance since the olive cultivar and its characteristics are directly related to olive oil quality [13]. Therefore, identification of the botanical origin as well as adulteration of olive oils with lower quality or less costly cultivars are some of the goals of authenticity research $[14,15]$.

Nowadays, investigation of one or more constituents (major and minor components) present in the olive oils is carried out addressing important information on olive cultivars and differentiating and comparing their botanical origin. For example, different studies from Italy, Greece, and Spain have been conducted to authenticate olive oils [16-19].

Although the number of Greek indigenous monocultivars is more than 40, with the most systematically cultivated variety being cv. Koroneiki, most of other local autochthonous monocultivars remain to be investigated in detail. In the coastline part of north-western Greece, and mainly in the regional units of Preveza, Parga, and Thesprotia, the dominant olive cultivar, yet poorly investigated, is a local variety named Lianolia Kerkyras. Lianolia Kekryras (referred to locally as Prevezana, Ntopia Pargas, Lianolia) is an indigenous olive cultivar, cultivated exclusively in the above-mentioned regions as well as in the island of Corfu (Kerkyra) in the Ionian sea [20,21]. It is a small-fruited cultivar with its fruits having an elongated cylindro-conical shape with a small nipple. Their weight ranges from 1.2-2.5 g and is normally harvested from late-November to late February. The oil content of Lianolia Kerkyras ranges from $18-20 \%$ and is considered as a variety of moderate productivity [20,21]. Respectively, Koroneiki is also a small-fruited cultivar with a cylindrical shape. The weight of Koroneiki olive fruit ranges from $0.6-1.5 \mathrm{~g}$ and its oil content from $22-25 \%$. It is considered as a variety of excellent productivity and resistance to adverse weather conditions [20,21].

According to our knowledge, monovarietal olive oils of Lianolia Kerkyras have never before been characterized in depth. There are, in fact, a few publications concentrated on the classification of different Greek monocultivar olive oils, among which Lianolia Kekryras was one of the examined cultivars; however, the first study focuses on the classification of Western Greece's monocultivar olive oils based on their volatile profile [22] and the other two studies focused on their geographical discrimination $[23,24]$.

Hence, the objective of this study was to evaluate and characterize monovarietal olive oils of cv. Lianolia Kerkyras produced in the coastline part of Western Greece and compare them with olive oils of Koroneiki variety produced in the same area. Free fatty acid, peroxide value, and UV absorption characteristics were analyzed as the quality parameters. Moreover, analysis of the sterolic and fatty acid profile were performed. In addition, emphasis was given on the potential of their discrimination for authenticity purpose in terms of their botanical origin. The identification of possible compositional markers was examined based on their chemical parameters. 


\section{Materials and Methods}

\subsection{Olive Oil Sampling}

One hundred and four $(N=104)$ virgin olive oil samples were taken during the harvesting period of 2019-2020 from the coastline part of Western Greece. In more detail, sixty (60) olive oil samples of Lianolia Kerkyras and forty four (44) samples of Koroneiki cultivar were originated from the following regional units: Preveza area (at $38^{\circ} 57^{\prime} 33.35^{\prime \prime} \mathrm{N}$ and $20^{\circ} 25^{\prime} 06.18^{\prime \prime} \mathrm{E}$ )Parga area (at $39^{\circ} 17^{\prime} 07.20^{\prime \prime} \mathrm{N}$ and $20^{\circ} 24^{\prime} 01.80^{\prime \prime}$ E) and Thesprotia area (at $39^{\circ} 29^{\prime} 36.60^{\prime \prime} \mathrm{N}$ and $20^{\circ} 22^{\prime} 42.76^{\prime \prime}$ E) according to Google Earth version 7.0.1.8244-beta, Google, Inc., USA). Similar climatic conditions were evident at all regions, characterized mainly by mild climate with temperatures rarely falling below freezing. Summer months are hot, and the weather is the typical Mediterranean weather with not so much rain but lots of sunlight. Olive fruits were derived from conventional agriculture and harvested between mid-November to February according to specific technical details provided by the responsible agriculturists in the framework of the project. Olive fruits were transferred to local oil mills, equipped with 2-phase centrifugal systems (decanters) in all cases and the olive oil was extracted within $24 \mathrm{~h}$ by using the same protocol for all samples and as such they were not treated as variables. This involved washing and crushing of olive fruits followed by olive paste malaxation at $27-29^{\circ} \mathrm{C}$ for $35-45 \mathrm{~min}$ and decanting. The resulting olive oil samples were transferred to $1 \mathrm{~L}$ air-tight dark-green glass bottles and stored at $4{ }^{\circ} \mathrm{C}$ in the fridge for analysis. All examined parameters were determined in duplicate.

\subsection{Analysis of the Quality Parameters}

Free fatty acid, peroxide value, and UV absorption characteristics $\left(\mathrm{K}_{232}\right.$ and $\left.\mathrm{K}_{268}\right)$ were determined as described by the analytical methods of Regulation EEC/2568/91 of the European Commission and later amendments [25].

\subsection{Analysis of the Sterolic Profile}

The oils, with the addition of $\alpha$-cholestanol as internal standard (Sigma, St. Louis, MO, USA), were saponified with $\mathrm{KOH}$ in an ethanolic solution and the unsaponifiable matter was then extracted with diethylether. Separation of the different alcoholic compounds fractions took place by thin-layer chromatography (TLC) on a basic silica gel plate (Fluka, St. Louis, MO, USA). The addition of the appropriate silylation reagent (Alfa Aesar GmbH \& Co., Karlsruhe, Germany) made possible the transformation of the recovered fractions into trimethyl-silyl-ethers. Analysis was performed by capillary column gas chromatography as described by EEC/2568/91 regulation, Annexes V [25].

\subsection{Analysis of the Fatty Acid Profile}

The principle of the method is based on the conversion through trans-esterification of the fatty acids into fatty acid methyl esters (FAME) and extraction with n-hexane. Analysis of the individual fatty acids was carried out according to Regulation EEC/2568/91, Annex IV with later amendments.

\subsection{Statistical Analysis}

The findings were presented as mean values \pm standard deviation (SD). The use MINITAB 18 software (MINITAB, INC. State College, PA, USA) was applied to analyze the samples. In addition, minimum and maximum values of the samples, mean, and standard deviation (SD) were collected. In the theory of statistics, an indication of statistical dispersion is provided by the difference between the biggest and smallest values (range). Moreover, in this study, the statistical mean differences were evaluated based on the statistical tool analysis of variation (ANOVA). A statistical significance level was set at $p<0.05$. The tests of normality and homogeneity for the variances were carried out, and we found that both conditions are satisfied. The principal component analysis (PCA) was also conducted to investigate the association of the two monocultivars with the chemical characteristics analyzed. 


\section{Results and Discussion}

\subsection{Quality Parameters of the Examined Olive Oils}

Injuries caused to the olive fruits from insect attacks and fungal diseases, improper olive harvest practices, and extraction methods as well as poor storage conditions of the extracted olive oil are the main factors affecting the quality characteristics of the produced olive oil [26]. Hence, categorization of the collected monovarietal olive oils took place by means of determination of free fatty acids, peroxide value, and spectrophotometric absorption. Table 1 shows that all analyzed samples obtained from the two examined cultivars in the coastline part of Western Greece belong to the highest quality category of "extra virgin olive oil" since they satisfy the specifications set by EU Regulation 2568/91 [25]. More specifically, the mean free fatty acid was $0.24 \%$ and $0.27 \%$, respectively for Koroneiki and Lianolia Kerkyras olive oils. Likewise, the mean peroxide value for $\mathrm{cv}$. Koroneiki olive oils was $6.64 \mathrm{meqO}_{2} \mathrm{~kg}^{-1}$ whereas for cv. Lianolia Kerkyras the mean peroxide value was $5.21 \mathrm{meqO}_{2} \mathrm{~kg}^{-1}$. Similarly, both monovarietal olive oils had $\mathrm{K}_{232}$ and $\mathrm{K}_{268}$ mean values quite below the limit set by the EU Regulation 2568/91. The results depict that both cultivars had an overall high quality profile in that crop year as far as their basic qualitative parameters is concerned.

Table 1. Quality indices for the examined Koroneiki and Lianolia Kerkyras olive oils from the coastline region of Western Greece.

\begin{tabular}{cccccc}
\hline \multirow{2}{*}{ Parameter } & \multicolumn{2}{c}{ cv. Koroneiki $(N=44)$} & \multicolumn{2}{c}{ cv. Lianolia Kerkyras $(N=60)$} & \multicolumn{2}{c}{ EEC Limit for Extra Virgin } \\
& Mean \pm SD & Min-Max & Mean \pm SD & Min-Max & Olive Oil (EVOO) Category \\
\hline $\begin{array}{c}\text { Free acidity }(\%) \\
\text { Peroxide value }\end{array}$ & $0.24 \pm 0.10$ & $0.13-0.55$ & $0.27 \pm 0.12$ & $0.12-0.75$ & $\leq 0.80$ \\
$\left(\mathrm{meqO}_{2} / \mathrm{kg}\right)$ & $6.64 \pm 1.26$ & $3.81-9.66$ & $5.21 \pm 1.12$ & $3.41-8.64$ & $\leq 20$ \\
$\mathrm{~K}_{232}$ & $1.56 \pm 0.14$ & $1.39-2.04$ & $1.61 \pm 0.15$ & $1.25-1.95$ & $\leq 2.50$ \\
$\mathrm{~K}_{268}$ & $0.14 \pm 0.01$ & $0.11-0.19$ & $0.14 \pm 0.02$ & $0.11-0.21$ & $\leq 0.22$ \\
\hline
\end{tabular}

Values are expressed as means \pm standard deviation (SD). $N=104$.

\subsection{Fatty Acid Profile of the Two Monocultivar Olive Oils}

Fatty acid profile plays an important role in the quality and characterization of an olive oil as its composition reflects the nutritional properties of an olive oil [27]. Several researchers have reported that among other major components, fatty acids composition seems to represent a possible tool for varietal characterization and authentication [28-33]. Table 2 shows the mean fatty acid composition of the analyzed monovarietal olive oils. As it is shown, all fatty acids identified were found in the normal range expected for the extra virgin olive oil category for both monocultivars. With respect to the mono-unsaturated oleic acid (C18:1), olive oils of cv. Koroneiki presented a higher concentration with a mean value of $75.07 \%$ compared to cv. Lianolia Kerkyras (69.55\%). Moreover, the saturated stearic acid (C18:0) concentration was higher for cv. Koroneiki with a mean value of $2.51 \%$ compared to the concentration of $2.04 \%$ for cv. Lianolia Kerkyras. On the other hand, olive oils of cv. Lianolia Kerkyras presented a clearly higher concentration of the poly-unsaturated linoleic acid (C18:2) with a mean value of $10.40 \%$ compared to the Koroneiki olive oils $(6.43 \%)$ as well as a higher concentration in palmitic acid (14.46\%). Regarding the comparison of the contents of the different lipids in the two varieties, the different flesh to stone ratio is characteristic of the olives themselves. The flesh to stone ratio is $3-4$ to $1 \mathrm{in} \mathrm{cv}$. Lianolia Kerkyras and 5 to $1 \mathrm{in} \mathrm{cv}$. Koroneiki, and the stone is relatively large in the latter, according to the catalogue of "Apulian and Greek Olive Varieties". This anatomical characteristic combined with the fact that the olive seeds are richer in linoleic acid and beta-sitosterol than the olive pulp [34] could explain the higher content of these components in cv. Lianolia Kerkyras. Moreover, the discrimination of the two varieties can also be aided and explained by the 18:1/18:2 ratio which indicates that the ratio in cv. Koroneiki is double that of cv. Lianolia Kerkyras. 
Table 2. Fatty acid profile of the examined monocultivar olive oils in the coastline region of Western Greece.

\begin{tabular}{|c|c|c|c|c|c|c|}
\hline \multirow{2}{*}{ Parameter } & \multicolumn{2}{|c|}{ cv. Koroneiki $(N=44)$} & \multicolumn{2}{|c|}{ cv. Lianolia Kerkyras $(N=60)$} & \multirow{2}{*}{$\begin{array}{c}\text { Calculated } \\
p \text {-Value }\end{array}$} & \multirow{2}{*}{$\begin{array}{l}\text { EEC Limit for } \\
\text { EVOO Category }\end{array}$} \\
\hline & Mean \pm SD & Min-Max & Mean \pm SD & Min-Max & & \\
\hline Myristic C14:0 (\%) & $0.009 \pm 0.002$ & $0.006-0.018$ & $0.008 \pm 0.004$ & $0.003-0.04$ & n.s & $\leq 0.03$ \\
\hline Palmitic C16:0 (\%) & $13.17 \pm 1.01$ & $11.16-17.59$ & $14.76 \pm 0.91$ & $12.97-16.71$ & 0.000 & $7.50-20.00$ \\
\hline Palmitoleic C16:1 (\%) & $1.07 \pm 0.17$ & $0.83-1.69$ & $1.47 \pm 0.19$ & $0.97-1.91$ & 0.000 & $0.30-3.50$ \\
\hline Heptadecanoic C17:0 (\%) & $0.04 \pm 0.01$ & $0.02-0.06$ & $0.04 \pm 0.01$ & $0.02-0.07$ & n.s & $\leq 0.40$ \\
\hline Heptadecenoic C17:1 (\%) & $0.07 \pm 0.01$ & $0.05-0.12$ & $0.08 \pm 0.01$ & $0.05-0.13$ & 0.003 & $\leq 0.60$ \\
\hline Stearic C18:0 (\%) & $2.51 \pm 0.24$ & $2.03-2.98$ & $2.04 \pm 0.15$ & $1.78-2.64$ & 0.000 & $0.50-5.00$ \\
\hline Oleic C18:1 (\%) & $75.07 \pm 1.71$ & $69.76-77.96$ & $69.55 \pm 1.71$ & $65.39-73.00$ & 0.000 & $55.00-83.00$ \\
\hline Linoleic C18:2 (\%) & $6.43 \pm 1.27$ & $4.21-9.55$ & $10.40 \pm 0.91$ & $8.30-12.80$ & 0.000 & $2.50-21.00$ \\
\hline Linolenic C18:3 (\%) & $0.72 \pm 0.07$ & $0.63-0.88$ & $0.79 \pm 0.08$ & $0.60-0.99$ & 0.000 & $\leq 1.00$ \\
\hline Arachidic C20:0 (\%) & $0.45 \pm 0.03$ & $0.34-0.53$ & $0.40 \pm 0.02$ & $0.30-0.49$ & 0.000 & $\leq 0.60$ \\
\hline Eicosenoic C20:1 (\%) & $0.29 \pm 0.04$ & $0.23-0.37$ & $0.28 \pm 0.03$ & $0.20-0.33$ & n.s & $\leq 0.50$ \\
\hline Behenic C22:0 (\%) & $0.13 \pm 0.02$ & $0.09-0.18$ & $0.13 \pm 0.02$ & $0.09-0.18$ & n.s & $\leq 0.20$ \\
\hline Lignoceric C24:0 (\%) & $0.05 \pm 0.02$ & $0.01-0.10$ & $0.05 \pm 0.01$ & $0.03-0.09$ & 0.009 & $\leq 0.20$ \\
\hline
\end{tabular}

Values are expressed as means \pm standard deviation (SD). n.s $=$ not-significant. The $p<0.05$ was set at the level of statistical significance.

Variability in fatty acid composition between the two monocultivar olive oil samples led to the performance of an analysis of variance (ANOVA) in order to assess their differences. Table 2 shows substantial statistical differences between Lianolia Kerkyras and Koroneiki samples in almost all the analyzed fatty acids $(p<0.05)$. The analysis of variance applied to the $13 \mathrm{GC}$ analyzed variables allowed the variables with the highest discriminant power to be determined. The more discriminant variables are $\mathrm{C} 18: 2(\mathrm{~F}=343.19), \mathrm{C} 18: 1(\mathrm{~F}=264.70), \mathrm{C} 18: 0(\mathrm{~F}=149.88), \mathrm{C} 16: 1(\mathrm{~F}=125.54), \mathrm{C} 16: 0(\mathrm{~F}=71.21)$, $\mathrm{C} 20: 0(\mathrm{~F}=65.71)$, and $\mathrm{C} 18: 3(\mathrm{~F}=22.28)$.

The effect of cultivar in the fatty acid profile of the two monocultivar olive oils originating from the coastline region of north-western Greece is depicted from the results of this work proving the usefulness of fatty acid composition for this varietal discrimination. Those results are in agreement with our previously published data as well as other relevant studies, demonstrating that fatty acid profile plays a crucial role in the classification of virgin olive oils according to their cultivar [28-33]. Finally, according to our findings, this local Greek olive variety has the tendency of exhibiting higher concentrations in the poly-unsaturated omega- 6 linoleic acid and lower concentration in the mono-unsaturated omega-9 oleic acid compared to the most systematically cultivated variety of cv. Koroneiki. Of course, further in-depth research for more crop years is necessary for the adequate characterization of the fatty acid profile of Lianolia Kerkyras olive oils.

\subsection{Sterolic Profile of the Two Monocultivar Olive Oils}

Phytosterols and triterpenic dialcohols belong to the unsaponifiable fraction of olive oil and constitute one of its minor components with an important health beneficial impact [35-37]. Many researchers have shown that each variety has a characteristic sterol "fingerprint", revealing that the sterolic profile can be used as a reliable indicator with a high discrimination potential for olive oil classification [38-43].

Taking into account the unexplored chemical characteristics of Lianolia Kerkyras, we employed the present study to determine and compare the sterolic profile of the Koroneiki and Lianolia Kekryras olive oils obtained from the coastline region of north-western Greece. The percentage of individual sterols as well as the concentrations of total sterols for the examined monovarietal olive oil samples are presented in Table 3. In general, total sterols concentration and individual sterols content of cv. Lianolia Kerkyras olive oil samples comply with the up to date EU legislation [18]. In contrast, olive oil samples of cv. Koroneiki showed lower concentration in total sterols with a mean value of $1020.8 \mathrm{mg} / \mathrm{kg}$ compared to olive oils of cv. Lianolia Kerkyras (1343.7 mg/kg). More precisely, $40.9 \%$ of the analyzed samples of $\mathrm{cv}$. Koroneiki did not exceed the defined limit of $1000 \mathrm{mg} / \mathrm{kg}$ for total sterols (EEC Regulation 2568/91) as illustrated in Figure 1. This observation is in agreement with results of our previous publication regarding the tendency of low total sterol concentration in Koroneiki olive oils of 
the southern Peloponnese, enhancing and clearly depicting an "intrinsic characteristic" for Koroneiki cultivar [44].

The European Commission Regulation (EEC 2568/91) imposes limits or ranges for each type of sterol and total sterols based on the natural levels found in traditional olive oil types [25]. Sterol profiles outside these limits, in combination with other chemical parameters, could theoretically suggest that the oil is not authentic. However, a number of cases have found olive oils which naturally exceed or subceed the limits for sterols [45,46]. Analysis of virgin olive oils from cv Koroneiki in completely different geographical regions such as Crete and Australia has also shown a tendency of low total sterol concentration $[47,48]$. Thus, low mean value in the concentration of total sterols may depict a "special and intrinsic characteristic" for Koroneiki cultivar in general, which has to do with the cultivar itself [44].

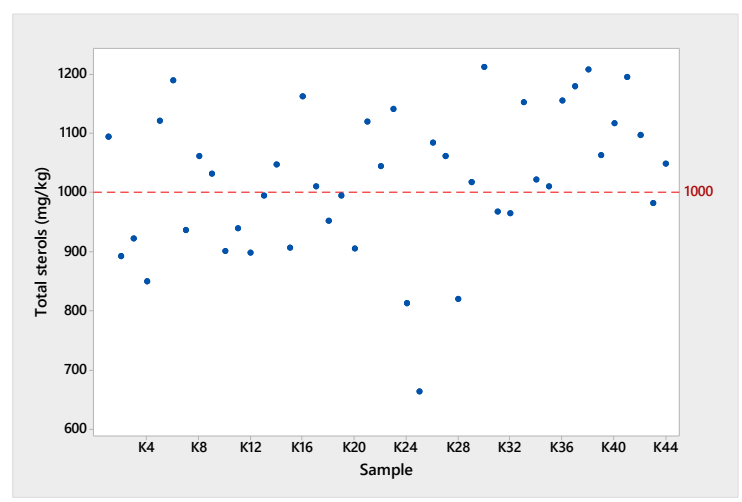

Figure 1. Diagram illustrating total sterols parameter $(40.9 \%$ of Koroneiki olive oil samples are below the set limit of $1000 \mathrm{mg} / \mathrm{kg}$ ). Dotted line represents the limit according to EEC/2568/91 for the EVOO category.

Table 3. Sterol profile of the examined monocultivar olive oils in the coastline region of Western Greece.

\begin{tabular}{|c|c|c|c|c|}
\hline & $\begin{array}{l}\text { cv. Koroneiki } \\
(N=44)\end{array}$ & $\begin{array}{c}\text { cv. Lianolia } \\
\text { Kerkyras }(N=60)\end{array}$ & $\begin{array}{c}\text { Calculating } \\
p \text {-Value }\end{array}$ & $\begin{array}{l}\text { EEC Limit for } \\
\text { EVOO Category }\end{array}$ \\
\hline Sterols and Triterpene Diols & Mean \pm SD & Mean \pm SD & & \\
\hline Cholesterol $(\%)$ & $0.10 \pm 0.08$ & $0.12 \pm 0.06$ & n.s & $\leq 0.5$ \\
\hline 24-methylene-cholesterol \% & $0.23 \pm 0.09$ & $0.08 \pm 0.04$ & 0.000 & \\
\hline Campesterol \% & $3.82 \pm 0.35$ & $3.42 \pm 0.17$ & 0.000 & $\leq 4.0$ \\
\hline Campestanol \% & $0.07 \pm 0.03$ & $0.04 \pm 0.02$ & 0.000 & $<$ campesterol \\
\hline Stigmasterol \% & $0.63 \pm 0.18$ & $0.49 \pm 0.15$ & 0.000 & \\
\hline Chlerosterol \% & $0.81 \pm 0.20$ & $0.81 \pm 0.16$ & n.s & \\
\hline$\beta$-Sitosterol \% & $85.95 \pm 2.68$ & $89.21 \pm 1.27$ & 0.000 & \\
\hline Sitostanol \% & $0.48 \pm 0.24$ & $0.69 \pm 0.17$ & 0.000 & \\
\hline$\Delta$-5-avenasterol \% & $6.93 \pm 2.38$ & $4.31 \pm 1.27$ & 0.001 & \\
\hline$\Delta-5,24$-stigm/dienol $\%$ & $0.29 \pm 0.14$ & $0.22 \pm 0.11$ & 0.002 & \\
\hline$\Delta$-7-stigmastenol \% & $0.32 \pm 0.15$ & $0.29 \pm 0.11$ & n.s & $\leq 0.5$ \\
\hline$\Delta$-7-avenasterol \% & $0.25 \pm 0.16$ & $0.26 \pm 0.11$ & n.s & \\
\hline Apparent b-Sitosterol \% & $94.63 \pm 0.70$ & $95.28 \pm 0.35$ & 0.000 & $\geq 93.0$ \\
\hline Total Erythrodiol \% & $2.76 \pm 1.07$ & $1.43 \pm 0.45$ & 0.000 & $\leq 4.5$ \\
\hline Total sterols (mg/kg) & $1020.8 \pm 120.7$ & $1343.7 \pm 115.1$ & 0.000 & $\geq 1000$ \\
\hline
\end{tabular}

Values are expressed as means \pm standard deviation (SD). n.s = not-significant. The $p<0.05$ was set at the level of statistical significance.

With respect to the profile of the individual sterols, Lianolia Kerkyras olive oils samples showed a higher mean value for the major phytosterol $\beta$-sitosterol (89.21\%) and for sitostanol (0.69\%) compared to the relative values of Koroneiki olive oil samples (Table 3). Moreover, Lianolia Kerkyras exhibited lower mean values for the most abundant sterols, namely $\Delta$-5-avenasterol $(4.31 \%)$, campesterol $(3.48 \%)$, 
stigmasterol $(0.49 \%)$, as well as for total erythodiol content $(1.43 \%)$. Although no previous reported data for the sterolic profile of cv. Lianolia Kerkyras is available, to the best of our knowledge, our results depict that this local Greek olive variety presents higher percentage mean values in $\beta$-sitosterol and total sterols compared to the most-known and exploited Koroneiki variety. The health-promoting aspects of $\beta$-sitosterol have been reported in several studies, recognizing its great hypocholesterolemic function in opposing the intestinal absorption of cholesterol and therefore contributing to the prevention of many diseases, including various types of cancer (colon, prostate, and breast) $[49,50]$.

Comparison of the two monocultivar olive oils according to their sterolic profile, as shown in Table 3, by means of the calculated $p$-value, shows it to be in most cases close to $0.00(p \approx 0.00)$, indicating a strong botanical effect. Thus, the dataset of individual and total sterols can enable the classification of the examined olive oils according to their cultivar and indicate them as a possible compositional marker for olive oil authentication. Future in-depth research by comparing the sterolic profile of olive oils derived from more olive cultivars would be advisable.

\subsection{Chemometric Analysis}

Principal component analysis (PCA) was carried out for the confirmation and strengthening of the classification of the examined monovarietal olive oils according to the cultivar. In order to restrict initial variables to a small number of new variables (known as principal components), the principal component analysis (PCA) is used to describe most of the original variations. The main goal of the key factor analysis is to identify the associated variables. The PCA score plot of Koroneiki versus Lianolia Kerkyras olive oils, according to their fatty acid and sterolic data set, is shown in Figure 2a,b respectively. In more detail, as shown in Figure 2a, the majority of K-points (corresponding to cv. Koroneiki) point to the left part of PC1, indicating that K has significant negative loads on component 2 . Moreover, it can be observed that L-points (corresponding to cv. Lianolia Kerkyras) are shown on the right part of $\mathrm{PC} 1$, meaning that $\mathrm{L}$ has significant positive loads on component 1 . Therefore, both $\mathrm{K}$ and $\mathrm{L}$ regions are independent and the data collection on fatty acids is not similar, impacting the two main regions. In accordance, the PCA score plot of Koroneiki vs. Lianolia Kerkyras olive oils' sterolic profile resulted in the creation of two separate clusters as shown in Figure 2b. In that case, we noted that L points are grouped very close to each other, depicting that the variability among Lianolia Kerkyras olive oils is very small compared to that of Koroneiki samples. A low variability for L points reveals that the samples appear to be very similar to the mean for the Lianolia Kerkyras, and therefore are not affected by any external factors.

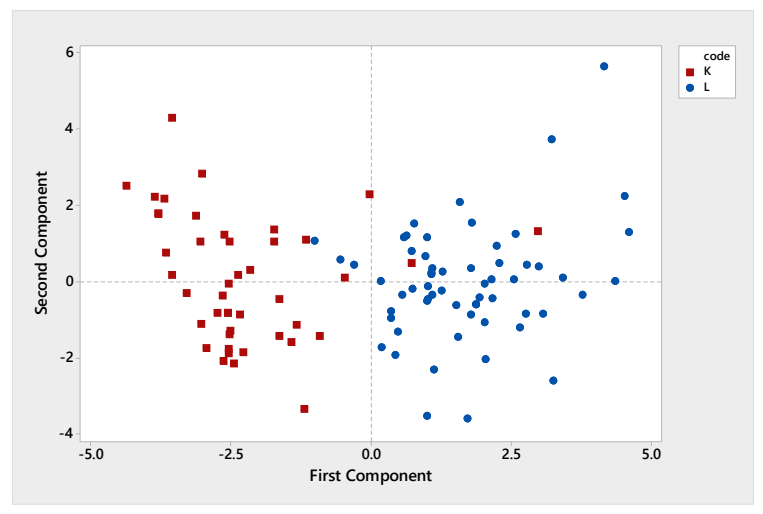

(a)

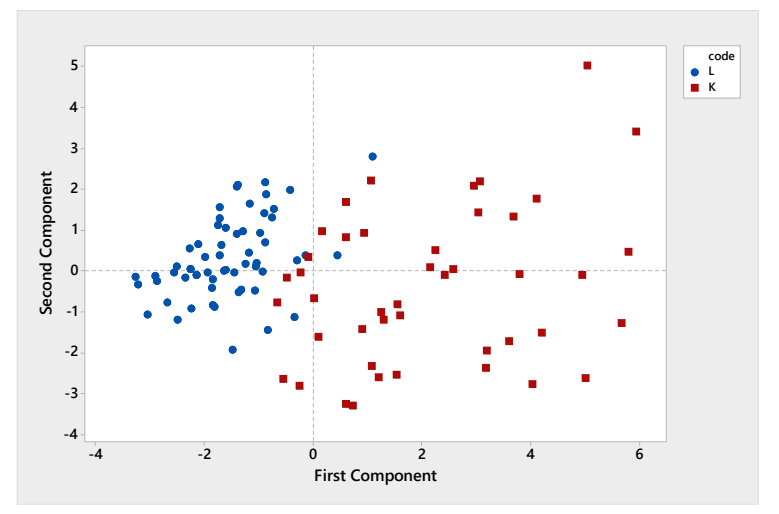

(b)

Figure 2. Score plot of principal component analysis (PCA) analysis based (a) on fatty acid (b) on the sterolic profiles of the examined monovarietal olive oils. K corresponds to Koroneiki olive oils (red spots) and L to Lianolia Kerkyras olive oils (blue spots). 
In general, a discrete separation between the two cultivars was detected by applying the PCA algorithm to the data set of fatty acids and sterols. The obtained results are in accordance with other relevant studies concentrating on olive oil major and minor compounds as effective tools for studying olive oil authentication. For example, fatty acid and triglyceride composition data have shown significant potential for olive oil classification according to cultivar [29-32]. Likewise, clear differences have been observed in the content of the fatty acid as well as phenolic content of Tunisian olive varieties [33]. In addition, according to Lorenzo et al., botanical discrimination of olive oils can be achieved by examining the variables of stearic acid, campesterol, total sterols, and oxidative stability [42]. Another research group has recently used both sterol and phenolic fingerprints to discriminate Tunisian and Italian EVOOs, outlining their potential for authenticity evaluations [43].

Finally, a combined PCA was performed using the variables of the fatty acid compositional and sterolic data (a total of 28 variables in 104 observations). As shown in the score plot of Figure 3, a complete separation according to the cultivar was achieved. Hence, it can be concluded that the discrimination of cv. Koroneiki and Lianolia Kerkyras samples in terms of cultivar could occur based on both fatty acid and sterolic profile data.

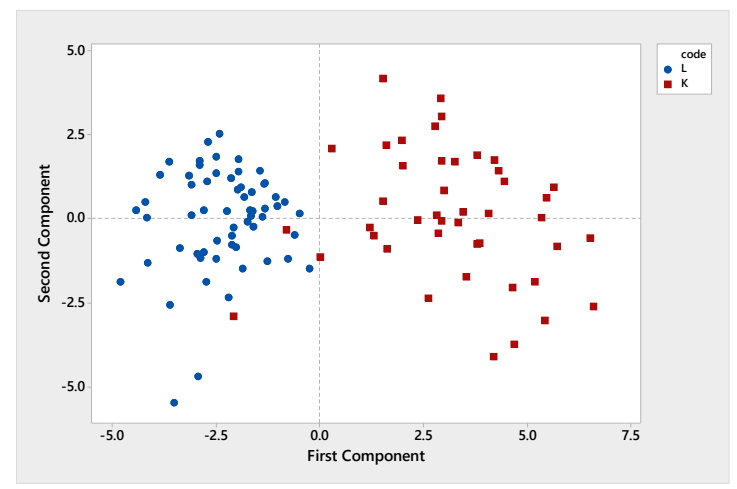

Figure 3. Score plot of PCA analysis based on 28 variables (combination of the sterolic and fatty acid data set) of the examined monovarietal olive oils. K corresponds to Koroneiki olive oils (red spots) and L to Lianolia Kerkyras olive oils (blue spots).

\section{Conclusions}

In the present study, we evaluated and profiled for the first time the chemical characteristics of Lianolia Kerkyras olive oils, a local Greek olive cultivar cultivated exclusively in the north-western coastline part of Greece as well as compared its chemical properties with those of the most well-known Greek olive cultivar, cv. Koroneiki. The high differentiation potential of sterols and fatty acid compositional data, as efficient authenticity tools for origin discrimination, was confirmed by employment of statistical analysis tools. The study and discrimination among local olive varieties is particularly important in order to preserve biodiversity and maintain the advantages of local varieties so as to promote and strengthen Greek olive sector. The obtained results not only lead to valuable information about the studied monocultivar olive oils, but can also contribute in the future to the establishment of a continuously enriched "Greek Authentic Olive Network" of indigenous, local, and less known and exploited monovarietal olive oils produced in Greece. Further in-depth research in combination with more examined parameters (e.g., sensory analysis, phenolic profile) and pioneering chemometric tools could secure the authenticity, traceability, and therefore higher commercial presence of Greek local olive varieties.

Author Contributions: Conceptualization, V.S., P.K., T.V.; methodology, V.S.; software, V.S.; validation, V.S., P.T.; formal analysis, V.S.; investigation, V.S., S.A., E.S.; resources, V.S.; data curation, P.T.; writing-original draft preparation, V.S., S.A., E.S., P.K., P.T., T.V.; writing-review and editing, V.S., A.S., E.S., P.K., P.T., T.V.; visualization, V.S., T.V.; supervision, T.V.; project administration, V.S., P.K.; funding acquisition, V.S., P.K., please turn to the CRediT taxonomy for the term explanation. All authors have read and agree to the published version of the manuscript. 
Funding: This research received funding under the project "Authentic Olive Net" in the framework of the European program "Interreg Greece Italy" MIS Code 5003145.

Conflicts of Interest: The authors declare no conflict of interest.

\section{References}

1. Boskou, D. Olive Oil: Chemistry and Technology, 2nd ed.; AOCS Press: Champaign, IL, USA, 2006; pp. 45-93.

2. Preddy, V.; Watson, R. Olives and Olive Oil in Health and Disease Prevention, 1st ed.; Academic Press: Oxford, UK, 2010; pp. 1100-1220.

3. Roche, H.M.; Gibney, M.J.; Kafatos, A.; Zampelas, A.; Williams, C.M. Beneficial properties of olive oil. Food Res. Int. 2000, 33, 227-231. [CrossRef]

4. Official Website of the European Union. An Overview of the Production and Marketing of Olive Oil in the EU. Available online: https://ec.europa.eu/info/food-farming-fisheries/plants-and-plant-products/plantproducts/olive-oil2020 (accessed on 20 July 2020).

5. International Olive Council Database. Available online: https://www.internationaloliveoil.org/what-we-do/ economic-affairs-promotionunit/\#exports (accessed on 10 July 2020).

6. Economic Affairs \& Promotion Unit, International Olive Council. Available online: https://www. internationaloliveoil.org/what-we-do/economic-affairs-promotion-unit/ (accessed on 12 July 2020).

7. Council Regulation (EC). No. 2081/92 of 14 July 1992 on the protection of geographical indications and designations of origin for agricultural products and foodstuffs. Off. J. Eur. Union 1992, L208, 1-8.

8. Council Regulation (EC). No. 2082/92 of 14 July 1992 on certificates of specific character for agricultural products and foodstuffs. Off. J. Eur. Union 1992, L208, 9-14.

9. Council Regulation (EC). No. 510/2006 of 20 March 2006 on the protection of geographical indications and designations of origin for agricultural products and foodstuffs. Off. J. Eur. Union 2006, L93, 12-25.

10. Council Regulation (EC). No. 1898/2006 of 14 December 2006 laying down detailed rules of implementation of Council Regulation (EC) no. 510/2006 on the protection of geographical indications and designations of origin for agricultural products and foodstuffs. Off. J. Eur. Union 2006, L369, 1-23.

11. Council Regulation (EC). No. 182/2009 of 6 March 2009 amending Regulation (EC) no. 1019/2002 on marketing standards for olive oil. Off. J. Eur. Union 2009, L63, 6-8.

12. Conte, L.; Bendini, A.; Valli, E.; Lucci, P.; Moret, S.; Maquet, A.; Lacoste, F.; Brereton, P.; García-González, D.L.; Moreda, W.; et al. Olive oil quality and authenticity: A review of current EU legislation, standards, relevant methods of analyses, their drawbacks and recommendations for the future. Trends Food Sci. Technol. 2019, (in press). [CrossRef]

13. Aparicio, R.; Luna, G. Characterization of monovarietal virgin olive oil. Eur. J. Lipid Sci. Technol. 2002, 104, 614-627. [CrossRef]

14. Montet, D.; Ray, R. Food Traceability and Authenticity, 1st ed; CRC Press: Boca Raton, FL, USA, 2018.

15. Montealegre, C.; Alegre, M.; García-Ruiz, C. Traceability markers to the botanical origin in olive oils. J. Agric. Food Chem. 2009, 58, 28-38. [CrossRef]

16. Bajoub, A.; Medina-Rodríguez, S.; Gómez-Romero, M.; Ajal, E.A.; Bagur-González, M.G.; Fernández-Gutiérrez, A.; Carrasco-Pancorbo, A. Assessing the varietal origin of extra-virgin olive oil using liquid chromatography fingerprints of phenolic compound, data fusion and chemometrics. Food Chem. 2017, 215, 245-255. [CrossRef]

17. Alonso-Salces, R.M.; Moreno-Rojas, J.M.; Holland, M.V.; Reniero, F.; Guillou, C.; Héberger, K. Virgin olive oil authentication by multivariate analyses of ${ }^{1} \mathrm{H}$ NMR fingerprints and $\delta^{13} \mathrm{C}$ and $\delta^{2} \mathrm{H}$ data. J. Agric. Food Chem. 2010, 58, 5586-5596. [CrossRef] [PubMed]

18. Longobardi, F.; Ventrella, A.; Napoli, C.; Humpfer, E.; Schütz, B.; Schäfer, H.; Kontominas, M.G.; Sacco, D. Classification of olive oils according to geographical origin by using ${ }^{1} \mathrm{H}$ NMR fingerprinting combined with multivariate analysis. Food Chem. 2012, 130, 177-183. [CrossRef]

19. Becerra-Herrera, M.; Vélez-Martín, A.; Ramos-Merchante, A.; Richter, P.; Beltrán, R.; Sayago, A. Characterization and evaluation of phenolic profiles and color as potential discriminating features among Spanish extra virgin olive oils with protected designation of origin. Food Chem. 2018, 241, 328-337. [CrossRef] [PubMed]

20. Kostelenos, G. Olive Fruit Data, History, Description and Geographical Distribution of Olive Varieties in Greece, 1st ed.; Kostelenos Georgios: Poros island, Greece, 2011; pp. 1-436. (In Greek) 
21. Kostelenos, G. Greek olive varieties. In Elaiokomia Egkiklopedia-The Olive Oil, 1st ed.; Zambounis, V., Ed.; Axion Ekdotiki: Athens, Greece, 2017; Volume 2, pp. 39-53. (In Greek)

22. Pouliarekou, E.; Badeka, A.; Tasioula-Margaria, M.; Kontakos, S.; Longobardi, F.; Kontominas, M.G. Characterization and classification of Western Greek olive oils according to cultivar and geographical origin based on volatile compounds. J. Chromatogr. A 2011, 1218, 7534-7542. [CrossRef]

23. Longobardi, F.; Ventrella, A.; Casielloa, G.; Sacco, D.; Tasioula-Margari, A.K.; Kiritsakis, A.K.; Kontominas, M.G. Characterisation of the geographical origin of Western Greek virgin olive oils based on instrumental and multivariate statistical analysis. Food Chem. 2012, 133, 1169-1175. [CrossRef]

24. Karabagias, I.; Michos, C.; Badeka, A.; Kontakos, S.; Stratis, I.; Kontominas, M.G. Classification of Western Greek virgin olive oils according to geographical origin based on chromatographic, spectroscopic, conventional and chemometric analyses. Food Res. Int. 2013, 54, 1950-1958. [CrossRef]

25. Commission Regulation (EEC). No. 2568/91 of 14 July 1991 on the characteristics of olive oil and olive-residue oil and on the relevant methods of analysis. Off. J. Eur. Union 1991, L208, 1-8.

26. Kiritsakis, A.; Christie, W. Analysis of edible oil. In Handbook of Olive Oil; Harwood, J., Aparicio, R., Eds.; Springer: Gaithersburg, MD, USA, 2000; pp. 129-158.

27. Boskou, D. Olive oil. In More on Mediterranean Diets; Simopoulos, A.P., Visioli, F., Eds.; Karger: Basel, Switzerland, 2007; Volume 97, pp. 180-210.

28. Di Bella, G.; Maisano, R.; La Pera, L.; Lo Turco, V.; Salvo, F.; Dugo, G. Statistical characterization of Sicilian olive oils from the Peloritana and Maghrebian zones according to the fatty acid profile. J. Agric. Food Chem. 2007, 55, 6568-6574. [CrossRef]

29. Ollivier, D.; Artaud, J.; Pinatel, C.; Durbec, J.P.; Guerere, M. Triacylglycerol and fatty acid compositions of French virgin olive oils. Characterization by chemometrics. J. Agric. Food Chem. 2003, 51, 5723-5731. [CrossRef]

30. D'Imperio, M.; Dugo, G.; Alfa, M.; Mannina, L.; Segre, A.L. Statistical analysis on Sicilian olive oils. Food Chem. 2007, 102, 956-965. [CrossRef]

31. Skiada, V.; Tsarouhas, P.; Varzakas, T. Comparison and discrimination of two major monocultivar extra virgin olive oils in the southern region of Peloponnese, according to specific compositional/traceability markers. Foods 2020, 9, 155. [CrossRef] [PubMed]

32. Stefanoudaki, E.; Kotsifaki, F.; Koutsaftakis, A. Classification of virgin olive oils of the two major Cretan cultivars based on their fatty acid composition. J. Am. Oil Chem. Soc. 1999, 76, 623-626. [CrossRef]

33. Krichene, D.; Taamalli, W.; Daoud, D.; Salvador, M.; Fregapane, G.; Zarrouk, M. Phenolic compounds, tocopherols and other minor components in virgin olive oils of some Tunisian varieties. J. Food Biochem. 2007, 31, 179-194. [CrossRef]

34. Alves, E.; Simoes, A.; Rosário Domingues, M. Fruit seeds and their oils as promising sources of value-added lipids from agro-industrial byproducts: Oil content, lipid composition, lipid analysis, biological activity and potential biotechnological applications. Crit. Rev. Food Sci. Nutr. 2020. [CrossRef]

35. Moreau, R.A.; Norton, R.A.; Hicks, K.B. Phytosterols and phytostanols lower cholesterol. Inform (Champaign) 1999, 10, 572-577.

36. Boskou, D.; Tsimidou, M.; Blekas, D. Olive Oil Chemistry and Technology; AOCS Press: Champaign, IL, USA, 2006; pp. 41-72.

37. López-Miranda, J.; Pérez-Jiménez, F.; Ros, E.; De Caterina, R.; Badimón, L.; Covas, M.I.; Escrich, E.; Ordovás, J.M.; Soriguer, F.; Abiá, R.; et al. Olive oil and health: In Proceedings of the II international conference on olive oil and health consensus report, Jaén and Córdoba, Spain. Nutr. Metab. Cardiovasc. Dis. 2010, 20, 284-294. [CrossRef]

38. Lukic, M.; Lukic, I.; Krapac, M.; Sladonja, B.; Pilizota, V. Sterols and triterpene diols in olive oil as indicators of variety and degree of ripening. Food Chem. 2013, 136, 251-258. [CrossRef]

39. Bucci, R.; Magrı', A.D.; Magrı, A.L.; Marini, D.; Marini, F. Chemical authentication of extra virgin olive oil varieties by supervised chemometric procedures. J. Agric. Food Chem. 2002, 50, 413-418. [CrossRef]

40. Matos, L.C.; Cunha, S.C.; Amaral,J.S.; Pereira,J.A.; Andrade, P.B.; Seabra, R.M.; Oliveira, B. Chemometric characterization of three varietal olive oils (cvs. Cobrancosa, Madural and Verdeal Transmontana) extracted from olives with different maturation indices. Food Chem. 2007, 102, 406-414. [CrossRef]

41. Brescia, M.A.; Alviti, G.; Liuzzi, V.; Sacco, A. Chemometrics classification of olive cultivars based on compositional data of oils. J. Am. Oil. Chem. Soc. 2003, 80, 945-950. [CrossRef] 
42. Lorenzo, I.M.; Perez Pavon, J.L.; Fernandez Laespada, M.E.; Garcia Pinto, C.; Moreno Cordero, B.; Henriques, L.R.; Peres, M.F.; Simoes, M.P.; Lopes, P.S. Application of headspace-mass spectrometry for differentiating sources of olive oils. Anal. Bioanal. Chem. 2002, 374, 1205-1211. [CrossRef] [PubMed]

43. Mohamed, M.B.; Rocchetti, G.; Montesano, D.; Ali, S.B.; Guasmi, F.; Grati Kamoun, N.; Lucini, L. Discrimination of Tunisian and Italian extra-virgin olive oils according to their phenolic and sterolic fingerprints. Food Res. Int. 2018, 106, 920-927. [CrossRef] [PubMed]

44. Skiada, V.; Tsarouhas, P.; Varzakas, T. Preliminary study and observation of "Kalamata PDO" extra virgin olive oil, in the Messinia region, southwest of Peloponnese, Greece. Foods 2019, 8, 610. [CrossRef] [PubMed]

45. Casas, J.S.; Bueno, E.O.; Garcia, A.M.M.; Cano, M.M. Sterol and erythrodiol uvaol content of virgin olive oils from cultivars of Extramadura (Spain). Food Chem. 2004, 87, 225-230.

46. Rivera del Alamo, R.M.; Fregapane, G.; Aranda, F.; Gomez-Alonso, S.; Salvador, M.D. Sterol and alcohol composition of Cornicabra virgin olive oil: The campesterol content exceeds the upper limit of $4 \%$ established by EU regulations. Food Chem. 2004, 84, 533-537. [CrossRef]

47. Mailer, R.J.; Ayton, J.; Graham, K. The Influence of growing region, cultivar and harvest timing on the diversity of Australian olive oil. J. Am. Oil. Chem. Soc. 2010, 87, 877-884. [CrossRef]

48. Stefanoudaki, E.; Chartzoulakis, K.; Koutsaftakis, A.; Kotsifaki, F. Effect of drought stress on qualitative characteristics of olive oil of cv Koroneiki. Grasas Aceites 2001, 52, 202-206. [CrossRef]

49. Awad, A.B.; Chan, K.C.; Downie, A.C.; Fink, C.S. Peanuts as a source of $\beta$-sitosterol, a sterol with anticancer properties. Nutr. Cancer 2000, 36, 238-241. [CrossRef]

50. Awad, A.B.; Chen, Y.C.; Fink, C.S.; Hennessey, T. Beta-Sitosterol inhibits HT-29 human colon cancer cell growth and alters membrane lipids. Anticancer Res. 1996, 16, 2797-2804.

(C) 2020 by the authors. Licensee MDPI, Basel, Switzerland. This article is an open access article distributed under the terms and conditions of the Creative Commons Attribution (CC BY) license (http://creativecommons.org/licenses/by/4.0/). 